\title{
Metal-Centered Oxidation Decreases Nitrile Hydration Activity of Bioinspired
}

\section{$\left(\mathrm{N}_{2} \mathrm{~S}_{3}\right) \mathrm{Ru}-\mathrm{PPh}_{3}$ Precatalysts}

Davinder Kumar ${ }^{1}$, Mark S. Mashuta ${ }^{1}$, and Craig A. Grapperhaus ${ }^{1}$ *

Department of Chemistry

University of Louisville

Louisville, KY 40292

(tel) 502-852-5932

(fax) 502-852-8149

grapperhaus@louisville.edu

1. Tel.: +1 502852 5932; fax: +1 5028528149 .

\section{Graphical Abstract}

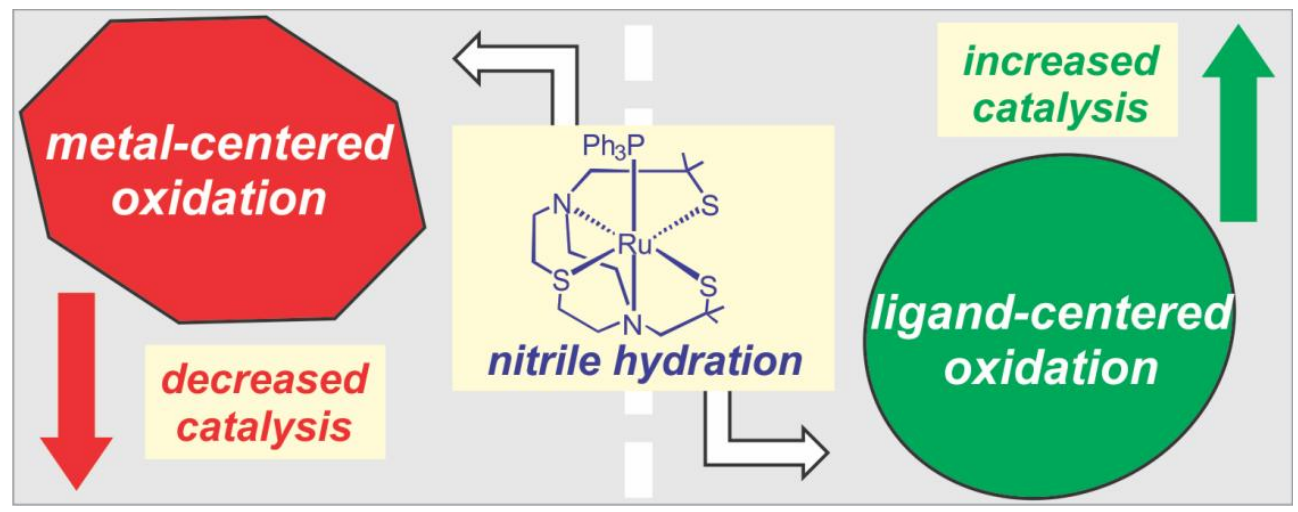




\begin{abstract}
A series of ruthenium(II) nitrile hydration catalysts based on the pentadentate ligand 4,7-bis(2'methyl-2'-mercaptopropyl)-1-thia-4,7-diazacyclononane and its sulfur-oxidized derivatives have been oxidized at the metal center yielding the ruthenium(III) counterparts. Metal-centered oxidation results in complete loss of nitrile hydration activity for the dithiolato (RS'/RS') parent complex. The sulfuroxidized thiolato/sulfinato $\left(\mathrm{RS}^{-}, \mathrm{RSO}_{2}{ }^{-}\right)$derivative displays a decrease in turnover number from $238 \pm 23$ to $3 \pm 1$ upon oxidation of $\mathrm{Ru}(\mathrm{II})$ to $\mathrm{Ru}(\mathrm{III})$. A similar decrease in turnover number from $242 \pm 23$ to $7 \pm 3$ is observed upon metal-centered oxidation of the sulfenato/sulfinato $\left(\mathrm{RSO}^{-}, \mathrm{RSO}_{2}{ }^{-}\right)$derivative. The inactive complex [(4,7-bis(2'-methyl-2'-mercaptopropyl)-1-thia-4,7-diazacyclononane)(triphenylphosphine)ruthenium(III)] hexafluorophosphate has been synthesized and characterized by electronic spectroscopy, electron paramagnetic resonance, and single crystal x-ray diffraction studies.
\end{abstract}

\title{
Keywords
}

ruthenium, metal-oxidation, sulfur-oxidation, nitrile hydration, nitrile hydratase 


\section{Text}

The selective hydration of nitriles to amides is catalyzed under ambient conditions by the metalloenzyme nitrile hydratase (NHase). Currently, NHase is used for the industrial scale production of acrylamide and more than ten other amides have been produced by NHase on a batch scale.[1-6] The active site of NHase contains a mononuclear low-spin non-heme iron(III) or non-corrin cobalt(III) center in an unusual $\mathrm{N}_{2} \mathrm{~S}_{3} \mathrm{X}$ type donor motif that contains two carboxamido nitrogens and three cysteine derived sulfur donors in distinct oxidation states; thiolate $\left(\mathrm{RS}^{-}\right)$, sulfenate/sulfenic acid ( $\left.\mathrm{RSO}^{-} / \mathrm{RSOH}\right)$ and sulfinate $\left(\mathrm{RSO}_{2}{ }^{-}\right)$as shown in Scheme 1.[7, 8] Although asymmetric sulfur-oxidation is crucial for the catalytic activity of NHase,[9] the Co(III) peptide maquettes of Shearer[10] and our Ru(II) bioinspired catalysts[11, 12] are the only two systems to have successfully implemented a mixed sulfenato/sulfinato donor set into a catalytically active synthetic system. In fact, the total number of functional NHase complexes remains small and limited to low-spin $d^{6} \mathrm{Co}(I I I)$ complexes, with the exception of our low-spin $d^{6} \mathrm{Ru}(\mathrm{II})$ catalysts.[11-16] To date, no functional NHase models with low-spin $d^{5}$ iron(III) centers are known despite its natural occurrence in the enzyme. Previously, we noted that aerobic conditions decreased the hydration activity of our Ru(II) catalyst 1, which was attributed to metal-centered oxidation since ferrocenium hexafluorophosphate $\left(\mathrm{FCPF}_{6}\right)$ had the same effect.[11] Herein we compare the effect of metal- versus ligand-centered oxidation on hydration activity through the oxidation of $\mathbf{1}-\mathbf{3}$ to their low-spin $d^{5} \mathrm{Ru}(\mathrm{III})$ derivatives $4-6$ with $\mathrm{FcPF}_{6}$ (Scheme 1). The Ru(III) complex $\mathbf{4}$ is also isolated and characterized by a variety of methods including x-ray crystallographic studies.

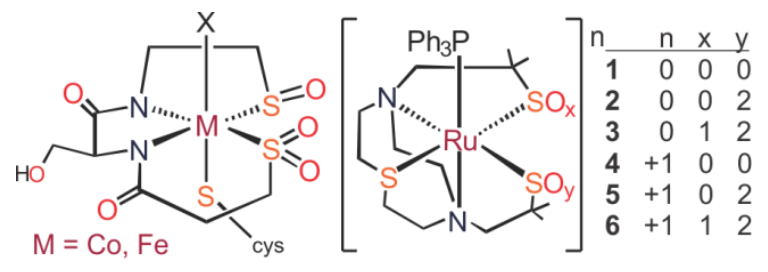

active site of NHase nitrile hydration precatalysts

Scheme 1. Active site of NHase and precatalysts 1-6. 
The previously reported dithiolato-Ru(II) precatalyst 1 displays a reversible oxidation at $-0.85 \mathrm{~V}$ versus ferrocenium/ferrocene $\left(\mathrm{Fc}^{+} / \mathrm{Fc}\right)$ in acetonitrile assigned to the $\mathrm{Ru}^{\text {III/II }}$ couple. The thiolato/sulfinato (2) and sulfenato/sulfinato (3) derivatives display $\mathrm{Ru}^{\mathrm{II} / \mathrm{ll}}$ couples at more positive potentials, -0.39 and $0.26 \mathrm{~V}$, respectively, due to the ligand-centered oxidations. $[17,18]$ The $\mathrm{Ru}(\mathrm{III})$ derivatives $4-6$ can be prepared by addition of ferrocenium hexafluorophosphate $\left(\mathrm{FCPF}_{6}\right)$ to the corresponding $\mathrm{Ru}(\mathrm{II})$ derivative. Addition of one equivalent of $\mathrm{FCPF}_{6}$ to $\mathbf{1}$ in dry degassed acetonitrile solvent afforded $\mathbf{4}$ in $96 \%$ isolated yield as a red-purple solid, which was further characterized. Additional synthetic details are provided in the Supporting Information. Precatalysts $\mathbf{5}$ and $\mathbf{6}$ were prepared using the same synthetic methodology from 2 and 3, respectively, and used in situ for catalytic assays without further characterization.

To determine the effect of metal-oxidation on nitrile hydration, we evaluated the catalytic activity of 4-6 for the hydration of benzonitrile under the biphasic conditions previously employed for $\mathbf{1}-\mathbf{3}$. For 4, a 1:1 mixture of benzonitrile and water containing 1 and $\mathrm{FCPF}_{6}$ was prepared under anaerobic conditions. Oxidation of 1 to $\mathbf{4}$ was noted by a color change from orange to red purple upon mixing. The reaction vial was sealed under argon and heated at $124{ }^{\circ} \mathrm{C}$ in an oil bath for 18 hours. Similar methods were employed for $\mathbf{5}$ and $\mathbf{6}$ with benzonitrile:water ratios of 1:7. Additional experimental details are provided in the Supporting Information. Following reaction, the organic product was isolated and analyzed via GCMS.

Oxidation of the metal-center significantly retards the nitrile hydration activity for all catalysts as shown in Table 1. Whereas 1 displays $91 \pm 3$ turnovers under 1:1 benzonitrile:water ratio,[11] 4 shows no detectable nitrile hydration activity under the same conditions. While 2 yields $238 \pm 23$ turnovers at a benzonitrile:water ratio of 1:7,[11] 5 only yields $3 \pm 1$ turnovers under those conditions. Similarly, $242 \pm$ 23 turnovers are observed for 3 at a benzonitrile:water ratio of 1:7, although only $7 \pm 3$ turnovers are observed for 6 . 


\begin{tabular}{|c|c|c|c|}
\hline Precatalyst & $\begin{array}{c}{[\mathrm{Ru}]} \\
\text { (ppm) }\end{array}$ & $\begin{array}{c}\mathrm{PhCN} / \mathrm{H}_{2} \mathrm{O} \\
(\mathrm{v} / \mathrm{v})\end{array}$ & TON \\
\hline 1 & 55 & 0.33 & $66 \pm 1$ \\
\hline 1 & 27 & 1.00 & $91 \pm 3$ \\
\hline 2 & 55 & 0.14 & $238 \pm 23$ \\
\hline 3 & 55 & 0.14 & $242 \pm 23$ \\
\hline 4 & 27 & 1.00 & 0 \\
\hline 5 & 55 & 0.14 & $3 \pm 1$ \\
\hline 6 & 55 & 0.14 & $7 \pm 3$ \\
\hline
\end{tabular}

Complex 4 was isolated as a red-purple solid from the oxidation of 1 with $\mathrm{FcPF}_{6}$ in acetonitrile. Oxidation of 1 to 4 shifts the charge transfer transition in the electronic spectrum from $438 \mathrm{~nm}$ to 521 $\mathrm{nm}$ consistent with the oxidation of the metal center. The ESI-MS parent peaks of $\mathbf{1}$ and $\mathbf{4}$ are observed at $\mathrm{m} / \mathrm{z}=684.11$ and 684.14 consistent with no change in the atomic composition of the metal-ion complex.[18] Likewise, the cyclic voltammogram of 4 displays a reversible event at $E_{1 / 2}=-844 \mathrm{mV}$ versus $\mathrm{Fc}^{+} / \mathrm{Fc}$ with the peak separation of $75 \mathrm{mV}$ consistent with the assigned Ru ${ }^{11 / / 1}$ couple of 1 . The X-band EPR spectrum of 4 exhibits an isotropic signal with $g=2.088$ with weak coupling to the $I=5 / 2$ nuclear spin of ${ }^{99,101} \mathrm{Ru}(29.8 \%)$ confirming an $\mathrm{S}=1 / 2$ spin-state, Figure 1.[19] Lahiri and coworkers observed a similar isotropic EPR spectrum for a low spin Ru(III) complex with dialkylthiophosphate donors.[20]

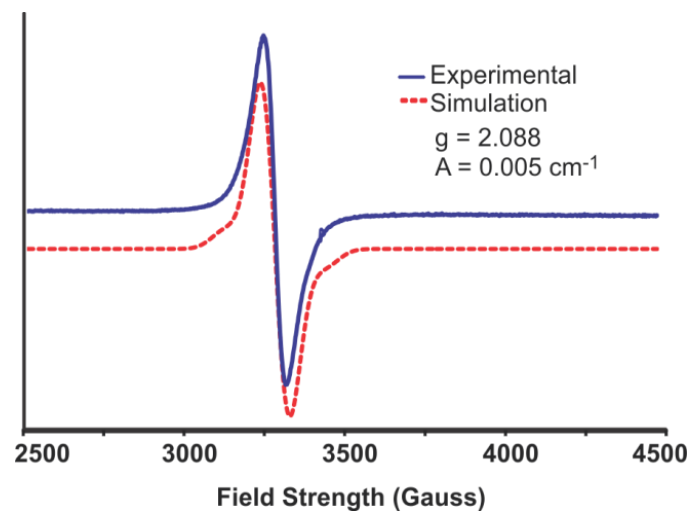

Figure 1. Experimental (solid-line) and simulated (dashed-line) $\mathrm{X}$-band EPR spectra of 4. Experimental: temperature $=77 \mathrm{~K}$, microwave frequency $=9.605 \mathrm{GHz}$, microwave power $=1.0 \mathrm{~mW}$, modulation amplitude $=5.0 \mathrm{G}$. Simulation with EasySpin (Reference 19): $\mathrm{g}_{\text {iso }}=2.088$, Aiso $\left({ }^{99,101} \mathrm{Ru}, 29.8 \%, \mathrm{I}=5 / 2\right)=0.005 \mathrm{~cm}^{-1}$, linewidth $=11 \mathrm{G}$. 
Complex 4 crystallizes as dark purple plates in the triclinic space group P-1. The X-ray analysis reveals that the $\mathrm{Ru}(\mathrm{III})$ cation of 4 is retained in a pseudo-octahedral $\mathrm{N}_{2} \mathrm{~S}_{3} \mathrm{P}$ environment similar to $1,[18]$ as shown Figure 2.[21] One face of the octahedron is defined by N1, N2, and S1 of the TASN ring, while the two pendant thiolates S2 and S3 are cofacial with the phosphorus donor P1. As detailed in Table 2, the effect of metal-oxidation, 1 versus $\mathbf{4}$, has a similar effect on metal-ligand bond distances as sulfuroxidation, 1 versus 3.[18] Oxidation increases the bond distances between the metal center and the soft phosphine (P1) and thioether (S1) donors. The Ru-P1 bond distance of 4, 2.3295(7) $\AA$, is intermediate between that of 1, 2.2911(10) $\AA$, and 3, 2.3790(9) $\AA$. The Ru-S1 bond distance of 4, 2.3602(8) $\AA$, is statistically equivalent to that of $3,2.3622(9) \AA$, and significantly longer than in $\mathbf{1}, 2.2900(10) \AA$. In contrast, oxidation decreases the metal-thiolate Ru-S2 bond distance due to a decrease in the metalligand $\mathrm{d} \pi-\mathrm{p} \pi$ antibonding interaction. The decrease in the Ru-S2 bond distance upon Metal-centered oxidation of 1 to 4 decreases the Ru-S2 bond by $0.163(1) \AA$, which is comparable to the $0.151(1) \AA$ decrease upon sulfur-oxidation from 1 to $\mathbf{3}$. Similar oxidation trends are observed in the smaller bond distance changes associated with N1, N2, and S3.

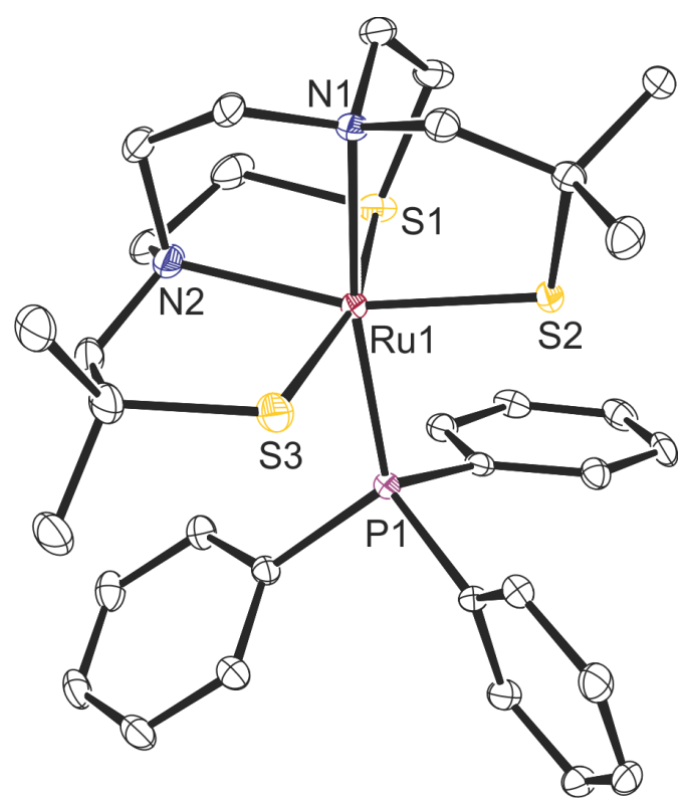

Figure 2. ORTEP[21] representation of the cation of 4 . 


\begin{tabular}{|c|c|c|c|}
\hline & 1 & 3 & 4 \\
\hline Ru-S1 & $2.2900(10)$ & $2.3622(9)$ & $2.3602(8)$ \\
\hline Ru-S2 & $2.4057(9)$ & $2.2548(9)$ & $2.2426(7)$ \\
\hline Ru-S3 & $2.3754(10)$ & $2.3493(9)$ & $2.3948(8)$ \\
\hline Ru-N1 & $2.198(2)$ & $2.178(3)$ & $2.185(2)$ \\
\hline Ru-N2 & $2.178(2)$ & $2.192(3)$ & $2.201(2)$ \\
\hline Ru-P1 & $2.2911(10)$ & $2.3790(9)$ & $2.3295(7)$ \\
\hline
\end{tabular}

It is interesting that oxidation at the metal or ligand-center has a similar influence on metalligand bond distances, but a distinct impact on nitrile hydration activity. Whereas ligand-centered oxidation enhances activity, metal-centered oxidation decreases activity. These results indicate that the enhancement of activity upon sulfur-oxidation cannot be attributed to a modulation of the Lewis acidity of the metal center and that other factors must be involved. In a classic study, Ford et al. noted that base hydrolysis of the coordinated nitrile of $\left[\left(\mathrm{NH}_{3}\right)_{5} \mathrm{Ru}-\mathrm{NCR}\right]^{\mathrm{n}+}$ proceeds six orders of magnitude faster for $\mathrm{Ru}(\mathrm{III})$ relative to $\mathrm{Ru}(\mathrm{II})$ due to enhanced Lewis acidity.[22] However, those reactions were stoichiometric as the reaction stopped at the corresponding amidate bound product. Also, Kovacs and coworkers noted that cobalt(III) based mimics lacking sulfur-oxidation also allow isolation of hydration intermediate complexes[23] and DFT studies by Himo suggest that Fe(III) stabilizes the anionic amidate.[24] The results of our current study suggest that sulfur-oxidation enhances dissociation of the amide product consistent with our prior kinetic assays on 1 - 3.[12]

The exact mechanism by which the amide product is released remains unclear at this time. A plausible mechanism involves $\mathrm{H}$-bonding interactions between amide product and sulfinate/sulfenate donors, which could promote metal-amide bond cleavage. In conclusion, metal-oxidation decreases nitrile hydration activity despite the enhanced Lewis acidity of the metal ion. However, sulfur-oxidation enhances activity in part due to its ability by enhance product dissociation. 


\section{Acknowledgement}

We acknowledge the National Science Foundation (CHE-0749965) for financial support. MSM thanks the Department of Energy (DEFG02-08CH11538) and the Kentucky Research Challenge Trust Fund for upgrade of our X-ray facilities.

\section{Supplementary Materials}

Experimental details and spectral data of $\mathbf{4}$ in PDF format. X-ray structural data for $\mathbf{4}$ in CIF format.

\section{References}

[1] S. Prasad, T.C. Bhalla, Biotechnol. Adv., 28 (2010) 725-741.

[2] J.A. Kovacs, Chem. Rev., 104 (2004) 825-848.

[3] P.K. Mascharak, Coord. Chem. Rev., 225 (2002) 201-214.

[4] T.C. Harrop, P.K. Mascharak, Acc. Chem. Res., 37 (2004) 253-260.

[5] D. Kumar, C.A. Grapperhaus, Sulfur-Oxygenation and FunctionalModels of Nitrile Hydratase, in: Bioinspired Catalysis, Wiley-VCH Verlag GmbH \& Co. KGaA, 2014, pp. 325-348.

[6] T. Yano, T. Ozawa, H. Masuda, Chem. Lett., 37 (2008) 672-677.

[7] S. Shigehiro, M. Nakasako, N. Dohmae, M. Tsujimura, K. Tokoi, M. Odaka, M. Yohda, N. Kamiya, I. Endo, Nat. Struct. Biol., 5 (1998) 347-351.

[8] A. Miyanaga, S. Fushinobu, K. Ito, T. Wakagi, Biochem. Biophys. Res. Commun., 288 (2001) 11691174.

[9] T. Murakami, M. Nojiri, H. Nakayama, M. Odaka, M. Yohda, N. Dohmae, K. Takio, T. Nagamune, I. Endo, Protein Sci., 9 (2000) 1024-1030.

[10] J. Shearer, P.E. Callan, J. Amie, Inorg. Chem., 49 (2010) 9064-9077.

[11] D. Kumar, C.A. Masitas, T.N. Nguyen, C.A. Grapperhaus, Chem. Commun., 49 (2013) 294-296.

[12] D. Kumar, T.N. Nguyen, C.A. Grapperhaus, Inorg. Chem., 53 (2014) 12372-12377.

[13] M. Rat, Rodolphe Alves d. Sousa, A. Tomas, Y. Frapart, J.-P. Tuchagues, I. Artaud, Eur. J. Inorg. Chem., 2003 (2003) 759-765.

[14] L. Heinrich, A. Mary-Verla, Y. Li, J. Vaissermann, J.C. Chottard, Eur. J. Inorg. Chem., (2001) 22032206.

[15] L.A. Tyler, J.C. Noveron, M.M. Olmstead, P.K. Mascharak, Inorg. Chem., 42 (2003) 5751-5761.

[16] T. Ozawa, T. Shibayama, T. Yano, Y. Funahashi, H. Masuda, Jpn. J. Appl. Phys., 50 (2011) 1-6.

[17] C.A. Masitas, M. Kumar, M.S. Mashuta, P.M. Kozlowski, C.A. Grapperhaus, Inorg. Chem., 49 (2010) 10875-10881.

[18] C.A. Masitas, M.S. Mashuta, C.A. Grapperhaus, Inorg. Chem., 49 (2010) 5344-5346.

[19] S. Stoll, A. Schweiger, J. Magn. Reson., 178 (2006) 42-55.

[20] P.U. Jain, P. Munshi, M.G. Walawalkar, S.P. Rath, K.K. Rajak, G.K. Lahiri, Polyhedron, 19 (2000) 801-808.

[21] L.J. Farrugia, J. Appl. Crystallogr, 30 (1997) 565.

[22] A.W. Zanella, P.C. Ford, Inorg. Chem., 14 (1975) 42-47.

[23] R.D. Swartz, M.K. Coggins, W. Kaminsky, J.A. Kovacs, J. Am. Chem. Soc., 133 (2011) 3954-3963.

[24] K.H. Hopmann, J.D. Guo, F. Himo, Inorg. Chem., 46 (2007) 4850-4856. 